\title{
SISTEMA INTERAMERICANO DE DIREITOS HUMANOS (SIDH): REFORMAR PARA FORTALECER *
}

Cristina Timponi Cambiaghi e

Paulo Vannuchi

O debate em curso sobre os impasses vividos pelo Sistema Interamericano de Direitos Humanos (SIDH) vem sendo pautado por argumentos de excessiva polarização. É hora de promover um empenho de moderação entre as partes antagonizadas, chamando a uma reflexão crítica mais serena e abrangente.

As controvérsias que dominam os duelos políticos e partidários nos diferentes países do continente não devem se refletir automaticamente, sem nenhum tipo de filtro racional, no debate e na pesquisa científica do ambiente acadêmico. Sem o adequado esforço de compreender o problema a partir de seus múltiplos ângulos, as discussões produzirão mais calor do que luz.

Algumas intervenções de respeitáveis intelectuais de renome mundial e de alguns atores credenciados na defesa dos direitos humanos na América Latina resumem as

\footnotetext{
* Este texto traz pequenos ajustes ao que foi apresentado na $2^{\mathrm{a}}$ edição do seminário Hemisphere in flux, realizado no Memorial da América Latina, São Paulo, em novembro de 2012. Também foi publicada uma versão reduzida dele em Foreign Affairs Latinoamerica, v.13, n.3, jul./set. 2013.
} 
dificuldades atuais em fórmulas simples que provavelmente não serão potentes para indicar os caminhos eficientes de superação.

Os problemas reais são complexos, profundos, resultam de prolongados antecedentes históricos e envolvem até mesmo a velha dicotomia entre gerações de direitos humanos, que esteve presente na redação da Declaração Universal de 1948 e resultou na aprovação, em 1966, pela Assembleia Geral da ONU, de dois distintos pactos para construir um instrumento com a força normativa que faltava à Declaração.

Caberia aprovar um pacto único e isso não ocorreu por força de graves divergências conceituais sobre a fundamentação dos direitos humanos e dos caminhos plausíveis para concretizá-los. No fundo, estava presente a tradicional contraposição entre os direitos de liberdade e os direitos de igualdade, que a Conferência de Viena buscou ultrapassar, 134 em 1993, enfatizando a ideia de indivisibilidade.

$\mathrm{Na}$ polêmica atual, vemos que Boaventura de Sousa Santos, brilhante professor de Coimbra, sociólogo especializado nos temas do direito, entusiasta do Fórum Social Mundial e consultor da Bolívia e do Equador na elaboração das ousadas constituições nacionais aprovadas, respectivamente, sob a liderança de Evo Morales e Rafael Correa, lançando em 2012 um apelo público sobre as controvérsias do Sistema de Direitos Humanos da Organização dos Estados Americanos (OEA) com raciocínios tão simplificados, que pouco lembram as sofisticadas formulações de livros seminais como Pela mão de Alice: o social e o político na pós-modernidade, de 1994, um dos primeiros exercícios sérios no sentido de repensar o projeto socialista após o desmoronamento do bloco soviético.

Diz o professor - a quem respeitamos muito - num apelo público que lançou como esforço para bloquear a programada reforma no Sistema de Direitos Humanos da OEA: 
Ao contrário do que pretende o neoliberalismo, o mundo só é o que é porque nós queremos. Pode ser de outra maneira se a tal nos propusermos. A situação é de tal modo grave que é necessário tomar medidas urgentes, mesmo que sejam pequenos passos. Essas medidas variam de país para país e de continente para continente, ainda que a articulação entre elas, quando possível, seja indispensável. No continente americano, a medida mais urgente é travar o passo à reforma da CIDH [Comissão Interamericana de Direitos Humanos] em curso. Nessa reforma estão particularmente ativos países com quem sou solidário em múltiplos aspectos de seu governo, o Brasil, o Equador, a Venezuela e a Argentina. Mas no caso da reforma da CIDH estou firmemente ao lado dos que lutam contra a iniciativa destes governos e pela manutenção do estatuto atual da CIDH [...] (Santos, 2012).

Santos conclui seu apelo listando os principais itens da reforma que deveriam ser evitados:

À revelia da CIDH e com fortes limitações na participação das organizações de direitos humanos, o Conselho Permanente da OEA prepara um conjunto de recomendações para serem apresentadas para aprovação na Assembleia Geral Extraordinária, o mais tardar até março de 2013 [...]. Do que se sabe, todas as recomendações vão no sentido de limitar o poder da CIDH para interpelar os Estados em matéria de violação de direitos humanos. Por exemplo: dedicar mais recursos à promoção dos direitos humanos e menos à investigação de violações; encurtar de tal modo os prazos de investigação que tornam impossível uma análise cuidada; eliminar do relatório anual a referência a países cuja situação dos direitos humanos merece 
atenção especial; limitar a emissão e extensão de medidas cautelares; acabar com o relatório anual sobre a liberdade de expressão; impedir pronunciamentos sobre as violações que pairam como ameaças, mas ainda não foram concretizadas. (Santos, 2012).

Dois meses antes, em junho de 2012, José Miguel Vivanco, expoente da Human Rights Watch, advogado chileno que teve papel relevante na fundação do Cejil (Center for Justice and International Law), umas das principais organizações que atuam como peticionárias junto ao sistema interamericano, e também militante conhecido por questionamentos duros aos governos da Colômbia (questão dos paramilitares) e da Venezuela (liberdade de imprensa), país de onde foi expulso em 2008, já tinha se manifestado em termos mais contundentes:

Corre grave perigo o instrumento mais valioso construído coletivamente neste hemisfério para defender e expandir os direitos humanos e as liberdades públicas. Trata-se da CIDH, a qual, para muitos observadores imparciais, é uma das poucas instituições da OEA que funciona com credibilidade [...] Ora, se este órgão foi tão bem-sucedido, por que se empreende uma verdadeira campanha contra ele? Muito simples: porque atingiu interesses importantes de governos com claras tendências autocráticas ou suficientemente poderosos para se sentirem desobrigados de prestarem contas de suas políticas ou práticas a um órgão de supervisão regional [...] Lamentavelmente, ao invés de liderar a proteção desta importante instituição, o Secretário Geral da OEA, José Miguel Insulza, se uniu àqueles que a debilitam [...] A ninguém surpreende que os governos da Aliança Bolivariana para os Povos da Nossa América (Alba) 
estejam satisfeitos com a possibilidade de participar de um processo de reforma da Comissão e de sua Relatoria. O que pode surpreender muitos é o fato de o Brasil também apoiar esta estratégia. É decepcionante que um país com aspirações de responsabilidades globais, inclusive em direitos humanos, e que afirma sua adesão ao multilateralismo, continue a boicotar a Comissão depois de esta ter tido a ousadia de solicitar-lhe informações sobre o impacto de um projeto hidrelétrico sobre comunidades indígenas do Amazonas (Vivanco, 2012).

Não seria difícil coletar outras formulações semelhantes a essas duas, no polo dos que se opõem à ideia de reforma do SIDH, por vislumbrar que sua intenção é de enfraquecimento e submissão do órgão aos governos dos Estados-membro. Tendo ou não reparos a determinados episódios e comportamentos da Comissão Interamericana de Direitos Humanos, instituição mais exposta a críticas e polêmicas do que a Corte sediada na Costa Rica, avalia-se que as propostas de reforma postas na mesa estão orientadas num sentido de regressão. Deveriam, portanto, ser rechaçadas.

No outro polo, não apenas o Secretário-Geral Insulza tem externado seu descontentamento diante de diversos aspectos do funcionamento do SIDH, que não ajudam a fortalecê-lo, como diversos países-membros, incluindo alguns com governos de orientação política à esquerda, já apresentaram reclamações contra problemas recorrentes. Assimetria na questão dos prazos, quebra de isonomia procedimental em processos semelhantes relacionados a distintos países, controvérsias sobre o emprego das chamadas medidas cautelares consignadas apenas em regulamento interno (e não na letra da Convenção Americana), assunção de autoridade judicante que caberia apenas à Corte, eis alguns dos tópicos em que países de inclinações políticas muito díspares convergem nas queixas. 
Com a Venezuela, em especial, a litigância foi se avolumando até o ponto em que o país decidiu se retirar do Sistema Interamericano dos Direitos Humanos, formulando por escrito argumentos e denúncias que ultrapassam, em muito, o tom já em si beligerante do citado artigo de Vivanco. No documento ${ }^{1}$ em que oficializou, em setembro de 2012, a quebra de compromisso com o Pacto de São José da Costa Rica, o Estado venezuelano acusa, sem meias palavras, a CIDH de colocar-se a serviço dos Estados Unidos em sua política hegemonista na região.

Pela enésima vez, o governo Chávez acusou a CIDH de ter apoiado o golpe de Estado desferido contra a legítima constitucionalidade venezuelana, em 2002, fazendo menção à lamentável correspondência dirigida pelo Secretário-Executivo da CIDH ao líder golpista e empresário Pedro Carmona, que não permaneceria no posto presidencial mais do que três dias, repelido por ampla mobi138 lização popular em favor do governo constituído e eleito pelo voto direto em pleito que não recebeu contestação, portando alguma consistência.

Depois de explicar que o estopim para o desligamento foi a decisão da CIDH em favor de Raul Diaz Peña, preso na Venezuela durante vários anos pela acusação de envolvimento em atentados terroristas contra as embaixadas da Colômbia e da Espanha, o governo Chávez condenou também o que seria um alinhamento prévio com o ponto de vista dos grupos empresariais de comunicação que participaram das articulações golpistas, deixando como único possível canal de rediscussão a futura constituição de algum outro organismos equivalente à atual Comissão, insinuando o interesse comum de outros Estados da

\footnotetext{
${ }^{1}$ Carta do Ministro do Poder Popular para Relações Exteriores da República Bolivariana da Venezuela, Nicolás Maduro Moros, ao Secretário-Geral da OEA, José Miguel Insulza, em 6 de setembro de 2012.
} 
região: "tomara nós tenhamos em algum momento uma comissão séria e que possamos lutar com outros governos pelos Direitos Humanos".

Como reagir à atitude radical adotada pela Venezuela? Multiplicar ataques contra seu governo em nome dos Direitos Humanos? Torcer para que outros países como a Bolívia, Equador, Nicarágua, El Salvador, quem sabe o governo brasileiro liderado pela ex-guerrilheira Dilma Roussef, sigam o mesmo caminho? Ou buscar algum tipo de recuo multilateral e novas pactuações? Negociar ou denunciar? Na conhecida formulação de Albert Hirschman (1970), exit or voice?

A pergunta é muito pertinente: para superar a crise atual do SIDH, o melhor caminho seria, de fato, opor-se a qualquer tipo de reforma? Ou trabalhar por reformas que busquem fortalecê-lo? As instituições acadêmicas e os ativistas do meio intelectual trarão contribuições cruciais e pistas claras para solução dos impasses apenas se conseguirem guardar distância de qualquer formulação maniqueísta e mergulharem num exame desarmado de problemas que são reais e claramente localizáveis de parte a parte.

Esse trabalho precisa partir de uma radiografia sintética do que é o SIDH e quais as tensões que vem enfrentando nos anos mais recentes. Deve perguntar as razões das controvérsias em curso e, por fim, examinar sem mistificações a importância da OEA, com suas ações positivas, mas também com seus graves erros históricos motivados pelo ambiente da Guerra Fria.

Rejeitar mistificações, aqui, significa dizer que ninguém pode esquecer que o organismo regional já convalidou episódios de violação massiva de direitos humanos, como foram o bloqueio econômico e militar a Cuba (cujos líderes passaram a referir-se à OEA como "Ministerio de las Colonias”) e a intervenção militar na República Domi- 
nicana, nos anos 1960, bem como sua impotência ou inoperância em crises como a Guerra das Malvinas, a intervenção militar dos Estados Unidos no Panamá e em Granada, golpes contra instituições democráticas em Honduras e no Paraguai, entre outras ações.

Significa sustentar, também, que a Guerra Fria, extinta de fato, segue viva e operante como verdadeiro fantasma assombrando determinadas retóricas de ultraesquerda ou o fundamentalismo belicoso da ultradireita norte-americana no eixo Reagan-Bush-Fox-Tea Party, felizmente impedida de retomar a Casa Branca após uma eleição rigorosamente empatada em novembro de 2012.

\section{Nascimento do sistema e evolução histórica}

O SIDH surgiu no contexto da evolução pós-guerra do direito internacional e em complementação sincrônica à construção do sistema universal de proteção que começou 140 a ser erguido com a Declaração da ONU de 1948. Tanto em escala mundial quanto continental, esse novo sistema representou uma reação normativa, jurídica, política, ética e moral ao extermínio provocado pela Segunda Guerra, com sua catastrófica destruição de vidas humanas, que atingiu o paroxismo no terror do holocausto.

Assumindo caráter progressista e inovador, o SIDH constituiu-se como sistema regional de proteção e defesa dos direitos humanos, contribuindo para a difusão regional da ideia de que o Estado não é o único sujeito de direito internacional, passando-se a aceitar o indivíduo como pleiteador de seus direitos no âmbito mundial. Tal movimento deu início à revisão do conceito tradicional de soberania do Estado, admitindo-se certo grau de intervenção internacional no contexto interno, em nome da garantia e do respeito aos direitos humanos.

Enfatize-se: deu início apenas. Haverá uma caminhada de décadas até se atingir o momento em que a maioria 
dos países signatários da Convenção Americana, ou os que reconhecem sua submissão aos dois organismos por ela consignados, internalizem, de fato, os preceitos normativos do Sistema em todo o arcabouço jurídico e constitucional de cada nação.

A CIDH, criada em 1959 pela OEA, com o papel de promover e proteger os direitos humanos na região, monitora a situação dos direitos humanos em todos os Estados da Organização, examina denúncias individuais e exerce atividades diversas, inclusive por meio de suas relatorias temáticas.

A Comissão já completava dez anos de existência quando veio à luz o instrumento prescritivo que lhe garantiu estrutura institucional abrangente e um pouco de força cogente, a Convenção Americana dos Direitos Humanos, em vigência a partir de 1978. Em 1982, passou a contar com seu equivalente jurisdicional, a Corte Interamericana dos Direitos Humanos, sediada em São José da Costa Rica, que emitiu sua primeira sentença apenas em 1988.

Na polêmica atual, uma análise dos diferentes ciclos políticos atravessados pelo Sistema em suas quatro ou cinco décadas de existência não vem recebendo a atenção devida. Cabe ressaltar a distância que separa o ciclo de ditaduras militares e de lutas de resistência que se alongou pela região nas décadas de 1960 e 1970, em nítido contraste com o ambiente constituído na primeira década do século atual, quando se multiplicaram governos democráticos com programas voltados ao enfrentamento da pobreza e das desigualdades na distribuição de renda, pela primeira vez em cinco séculos.

No que se refere ao Brasil, por exemplo, vale registrar que a atuação da CIDH foi praticamente irrelevante no enfrentamento das torturas e violações sistemáticas de direitos humanos de cidadãos, sobretudo jovens, engajados na resistência política - com ações armadas ou não - à ditadura instalada em 1964. Jamais formulou qualquer iniciati- 
va contra megaprojetos como a Itaipu Binacional, a Rodovia Transamazônica, a Usina Nuclear de Angra e a Ponte Rio-Niterói, que dizimaram grupos indígenas, devastaram a floresta tropical, resultaram na morte de centenas de trabalhadores semiescravizados em gigantescos canteiros de obras, e ainda, no caso da Itaipu, agrediram a soberania do povo paraguaio.

Já com relação a regimes ditatoriais implantados uma década mais tarde, como o de Pinochet e dos generais argentinos, a atuação da CIDH adquire importância crescente, atingindo seu auge na corajosa visita da Comissão à Argentina, gesto que contribuiu para refrear o ímpeto genocida que atingiu o assombroso patamar de $30 \mathrm{mil}$ mortes e desaparecimentos forçados em seis anos de continuado terror de Estado.

Essa diacronia precisa ser levada em conta ao analisar algumas das reações equivocadas de governos como os do 142 Peru, da Venezuela, da Colômbia e mesmo do Brasil diante de intervenções que só podem ser adotadas pela $\mathrm{CIDH}$ ou pela Corte neste momento atual em que o SIDH já adquiriu maturidade, conquistou respeito e credibilidade, ao mesmo tempo que o fim da Guerra Fria e o avanço da democracia em escala regional convidam os Estados-membros a reagirem sem a truculência que era própria do período ditatorial.

Analisando a evolução do direito internacional dos direitos humanos, merece citação o balizamento sequencial proposto por Norberto Bobbio (2004) em seu livro $A$ era dos direitos: "os direitos humanos nascem como direitos naturais universais, desenvolvem-se como direitos positivos particulares (quando cada Constituição incorpora Declarações de Direito), para finalmente encontrarem sua plena realização como direitos positivos universais".

No contexto histórico do Brasil, somente após a democratização do país, com a edição da Constituição de 1988, 
também conhecida por "Constituição Cidadã", começa a adquirir consistência e se concretizar esse processo evolutivo de garantias dos direitos fundamentais. Apesar de o Brasil ter sido um dos últimos Estados-membros a aderirem à Convenção Americana dos Direitos Humanos, em 1992, aceitando a jurisdição da Corte a partir de 1998, pode-se afirmar, hoje, que o país teve um rápido avanço na incorporação dos direitos por ela protegidos em seu ordenamento jurídico interno.

Num balanço abrangente, é inquestionável que o SIDH, com seus dois braços, exerceu um papel fundamental na consolidação da democracia no continente americano a partir da segunda metade da década de 1970, garantindo uma via subsidiária e suplementar às vias internas nos casos de violações de direitos humanos.

Os Estados-membros da Convenção Americana, ao assumirem o compromisso de respeitar seus dispositivos, se comprometem a não violar os direitos ali protegidos, mas também a assegurar o livre e pleno exercício desses direitos a todos os seus cidadãos. Partindo desse pressuposto, é dever de cada Estado-membro promover o Sistema Interamericano e torná-lo acessível àqueles que sintam seus direitos violados, sem obter acolhida aos seus clamores no sistema interno de proteção.

Como todos sabem, os países da região já avançavam em vigoroso impulso de redemocratização ao longo dos anos 1980, quando a queda do Muro de Berlim - 1989 deu início ao desmoronamento-relâmpago do bloco soviético, concluído em 1992, ano em que o desaparecimento da União Soviética simboliza cronologicamente o fim da Guerra Fria.

$\mathrm{Na}$ onda triunfalista que levou Fukuyama (1992) alguém se lembra dele? - a decretar com alta pretensão o "fim da história", a América Latina mergulhou, durante os anos 1990, no fracassado ciclo neoliberal, cujo receituário 
estava sintetizado no chamado Consenso de Washington, que prescrevia enxugamento do Estado, flexibilização de direitos sociais dos trabalhadores, redução de gastos previdenciários, privatizações em massa, quebra de barreiras alfandegárias, supremacia do mercado como organizador da Nação.

Os desastrosos resultados que se seguiram em termos de desemprego, estagnação econômica, e agravamento das condições de extrema pobreza e surtos de violência propiciaram a germinação de um ciclo histórico oposto, de valorização da sensibilidade social, de esforços para enfrentamento das desigualdades econômicas entre classes e regiões, de resgate do papel do Estado como vetor e indutor do crescimento, fortalecimento das instituições políticas, soberania e independência no plano diplomático.

Qualquer análise do SIDH que ignore o necessário esforço para reconhecer e compreender essa alternância 144 de ciclos, desprezando as profundas mudanças em curso neste início de século XXI, pouco contribuirá para responder adequadamente à dúvida mais importante que este texto busca aflorar. O dilema está em optar pelo bloqueio a qualquer reforma ou discutir qual reforma se faz necessária para garantir maior fortalecimento do Sistema nesse contexto político inteiramente novo, vivido por um hemisfério em fluxo, onde torturados de ontem se converteram em mandatários de vários países.

\section{Problemas de um sistema que cresceu}

$\mathrm{O}$ crescimento expressivo do número de casos levados à CIDH a cada ano, o fortalecimento de sua autoridade política, o avanço dos organismos de representação (e de petição) com que a sociedade civil passou a contar nos diferentes países, o fortalecimento vigoroso da institucionalidade democrática em todos eles, tudo isso opera no sentido de exigir que o SIDH adquira estrutura mais robusta. 
Etapa inadiável desse fortalecimento seria resolver de forma consistente e duradoura a questão nevrálgica de seu financiamento precário, que limita drasticamente o campo de ação da Comissão e da Corte, além de estimular nuvens de suspeita - paranoicas ou não - a respeito dos aportes decisivos ministrados pelos Estados Unidos, país que, no entanto, se coloca a salvo de qualquer monitoramento ou sanção.

O necessário fortalecimento exige algo ainda mais difícil - quase impossível -, que é operar com eficiência o delicado trade-off entre o imperativo de conquistar credibilidade crescente junto à sociedade civil de todas as Américas, em especial junto às vítimas de violações e aos organismos peticionários, e as rígidas constraints que decorrem do fato de ser o SIDH um mecanismo oficial constituído pelos Estados da região, com todos os corolários hierárquicos, burocráticos e conservadores resultantes desse status.

Cada movimento, cada recomendação, cada intervenção dos comissionados da CIDH, dos juízes da Corte, dos técnicos e especialistas de ambos os organismos, trata de buscar sempre um adequado ponto de equilíbrio (balance) entre dois caminhos que seriam igualmente danosos.

Um deles seria se curvar às pressões e resistências opostas pelos Estados-membros, sempre incomodados e até mesmo raivosos diante de todo tipo de monitoramento, medidas cautelares ou sanções. Esse caminho resultaria na total falência do Sistema, cuja razão de ser é o exercício mesmo desse conjunto de controles.

O outro caminho prejudicial seria o Sistema alinhar-se previamente com os peticionários, tendo sempre o Estado como inimigo. Significaria desconsiderar os palpáveis avanços obtidos em anos recentes na região, ou imaginar de modo fantasioso que o SIDH pode atuar com a mesma autonomia e com a liberdade completa de um organismo que tivesse nascido no Fórum Social Mundial ou em qual- 
quer outra esfera autônoma da sociedade civil. Sonho que pode se converter num projeto histórico desejável para o futuro, mas que, obviamente, não corresponde à verità effettuale da OEA realmente existente nos dias de hoje.

O Sistema se condenará ao completo fracasso se cometer o equívoco de fugir a esse difícil trade-off pela obtusa via do entrincheiramento em "critérios técnicos", evitando qualquer tipo de avaliação política dos mutantes cenários nacionais. Essa atitude, de mais a mais, resvalaria pelas pregações da mídia, que associa a vida política a um mar de lama, enfoque sibilino mediante o qual a chamada "livre empresa" gostaria de ser mitificada como impecável espelho das virtudes humanas.

Uma pretensa imparcialidade absoluta dos membros da Comissão, da Corte e dos respectivos corpos de especialistas de ambos os organismos, no que se refere às controvérsias de natureza política e jurídica de cada país, sempre 146 inevitáveis no exame de cada caso, só poderia ser imaginada num coletivo composto por verdadeiros deuses do direito, da política e dos direitos humanos.

Sendo a luta pela consolidação histórica dos direitos humanos, desde sempre, uma luta travada por seres humanos, estará ela sempre palmilhada por contraditórias leituras dos fatos, desacordos sobre a melhor maneira de evitar violações e sancionar violadores, alinhamentos ou simpatias maiores e menores a respeito dos atores principais na sociedade civil e nos poderes públicos de cada país.

Equívoco brutal seria, por exemplo, nos temas vinculados à liberdade de imprensa e de expressão, um alinhamento ingênuo do SIDH com a agenda da Sociedad Interamericana de Prensa (SIP), que trava batalhas virulentas contra os principais governos latino-americanos que se afastaram dos ditames do Consenso de Washington e desenvolvem diplomacia soberana mediante as pressões norte-americanas que remontam ao surgimento da Doutrina Monroe. 
É sabido que os grupos empresariais e veículos de mídia articulados politicamente na SIP, incluindo El Mercurio, El Clarín, La Nación, O Estado de S. Paulo, O Globo, e vários outros, desempenharam papel expressivo na defesa das ditaduras que violaram massivamente os direitos humanos durante décadas. Assim, cada medida do SIDH em favor de grupos e veículos que ainda ostentam as mãos sujas de sangue precisa ser recoberta de cautelas especiais e explicações exaustivas para que ninguém possa identificar a Comissão ou a Corte com as forças políticas e partidos nacionais que lutam para derrotar - eleitoralmente ou não - os governos mais à esquerda de países como Brasil, Argentina, Uruguai, Bolívia, Equador, Peru, Venezuela, El Salvador, Nicarágua, entre outros.

Mesmo um estudo superficial das atividades da Comissão e da Corte na última década apontará problemas novos, que não se eram mencionados dez anos atrás, quando o Sistema ainda não tinha atingido a dimensão e a autoridade de hoje. Representantes oficiais dos Estados-membros, mas também especialistas conceituados, e até mesmo algumas entidades que atuam junto ao Sistema como peticionárias costumam apresentar dúvidas, indagações, sugestões e propostas concretas de mudança.

Ao mesmo tempo que se deseja maior publicidade e amplo acesso ao SIDH, em nome de sua universalidade, receia-se que o constante aumento do número de casos apresentados possa ser um entrave na promoção da justiça, reproduzindo-se em âmbito regional as inúmeras dificuldades encontradas no contexto interno dos países, dentre elas a excessiva demora dos procedimentos judiciais.

A aplicação dos mecanismos previstos no SIDH não deve afastar a responsabilidade primária dos Estados na proteção dos direitos humanos, devendo a instância internacional ser acionada de maneira suplementar, adicional e subsidiária, nas situações em que se pressuponha o esgo- 
tamento dos recursos internos. O consentimento voluntário do Estado com o controle e a fiscalização internacional nos casos de violação a direitos fundamentais deve estar vinculado necessariamente a falhas ou omissões nas respostas dos órgãos nacionais às referidas violações.

Assim, o SIDH não deve ser interpretado como instância recursal das decisões internas, quando elas tenham sido proferidas em conformidade com os parâmetros e as obrigações internacionais assumidos pelos Estados no que diz respeito aos direitos humanos. Nesse sentido, afirma Cançado Trindade (1996):

Os Tribunais internacionais de direitos humanos existentes - as Cortes Europeia e Interamericana de Direitos Humanos - não "substituem" os Tribunais internos, e tampouco operam como tribunais de recursos ou cassação de decisões dos Tribunais internos.

148 Não obstante, os atos internos dos Estados podem vir a ser objeto de exame por parte dos órgãos de supervisão internacionais, quando se trata de verificar a sua conformidade com as obrigações internacionais dos Estados em matéria de direitos humanos.

É papel dos Estados promover o SIDH e contribuir para que o seu acesso seja facilitado a qualquer pessoa ou entidade que julgue ter sido vítima de violações. Todavia, cumpre ressaltar que os requisitos de admissibilidade devem ser respeitados em nome da segurança jurídica e da valorização da instância regional. A admissão indiscriminada de casos coloca em risco a credibilidade e a funcionalidade do Sistema, ameaçando sua eficácia e eficiência na promoção e proteção dos direitos humanos em todas as partes do continente americano.

Importante salientar que não interessa às Américas um sistema sobrecarregado, inadequadamente financiado e 
questionado quanto ao equilíbrio e à eficácia de suas decisões. Nesse sentido, vale refletir quanto aos critérios de seleção dos casos e o impacto real que as decisões a eles relacionadas terão no contexto regional. Decisões que contemplem exclusivamente direitos individuais, e não coletivos, e que não venham a promover mudanças significativas na ordem interna de um país devem ser questionadas por suas limitações e por sua insuficiência.

O número crescente de petições recebidas pela Comissão e a falta de critérios mais precisos para a sua admissibilidade fazem com que o tempo de duração entre o recebimento da denúncia e a solução do caso (quer pela via da solução amistosa, quer pela via do cumprimento de recomendações pelo Estado, ou ainda pela decisão de encaminhar a demanda à Corte) seja excessivamente longo.

Deve-se atentar para o risco de o procedimento naquela instância repetir as mesmas falhas e imperfeições dos sistemas judiciais nacionais, no que diz respeito à celeridade. Constata-se não haver parâmetros fixos para o tempo médio de tramitação de um caso na Comissão e percebe-se, ainda, que não há uma lógica objetiva na seleção dos casos que serão impulsionados pela própria CIDH. É condenável a utilização de critérios seletivos na decisão discricionária de privilegiar casos de maior "visibilidade", em detrimento daqueles de menor alcance.

Com relação ao tempo de duração dos procedimentos na Corte, nota-se ser mais curto e mais previsível do que na Comissão, o que acaba por conferir maior credibilidade àquela instância, que segue avançando em seus trabalhos sem sofrer questionamentos comparáveis aos que são dirigidos contra a Comissão.

Não há que se falar em duplicação de funções entre a Comissão e a Corte. Ambas devem atuar com independência e respeitando suas competências. Apesar de a Corte reproduzir o processo de produção de provas e realização de 
audiências que também ocorre na Comissão, o enfoque dado ao tema é distinto. Quando o caso se encontra em análise na Corte, as partes do processo passam a ser, de um lado, o Estado e, de outro, a Comissão e os peticionários. Dessa forma, tanto as provas produzidas pelo Estado, quanto aquelas produzidas pela Comissão e pelos peticionários serão igualmente avaliadas, sem distinção.

A "igualdade de armas" estaria prejudicada, perante a Corte, se uma das partes do processo, no caso a Comissão, fosse num momento preliminar responsável pela valoração das provas apresentadas pelo Estado. Para que isso fosse possível, respeitando-se a independência processual, a Comissão não poderia ser parte interessada no processo perante a Corte, devendo exercer um papel mais próximo ao de Ministério Público ou Fiscalía.

A Corte Interamericana de Direitos Humanos, tal como sua correspondente europeia, passou a admitir a 150 participação das vítimas durante todo o processo, depois de aceita a demanda, sendo-lhes permitido apresentar suas petições, argumentos e provas de forma autônoma. Apesar de se considerar de extrema importância que, no futuro, o indivíduo possa acessar a Corte diretamente, hoje resta prejudicada a defesa do Estado no que diz respeito ao seu tempo de exposição oral. Atualmente, tanto a Comissão quanto as vítimas têm igual oportunidade de apresentação de provas e de manifestação, enquanto o Estado não teve aumentado seu tempo para defesa, gerando certo desequilíbrio processual.

\section{Medidas cautelares}

Os mecanismos de medidas cautelares e provisórias têm exercido importante papel na eficácia da proteção de direitos em casos em que sejam identificados os elementos de extrema gravidade e urgência. Nota-se que, quando conta com a cooperação dos Estados-membro no cumpri- 
mento das determinações, tal mecanismo se torna um verdadeiro aliado na prevenção de violações e na solução de situações de risco iminente de violação.

Vale salientar que a Convenção Americana prevê, em seu artigo 63, parágrafo 2, a possibilidade de a Corte decretar medidas provisórias, porém nada menciona sobre a função da Comissão no tocante a decretar medidas cautelares. Tal possibilidade é prevista apenas no Regulamento da Comissão (artigo 25), o que pode suscitar questionamentos sobre a legitimidade do referido mecanismo quando determinado por essa instância regional.

Talvez fosse mais produtivo para o Sistema se a Comissão se limitasse ao papel de avaliação rigorosa dos pedidos de medidas provisórias à Corte, evitando-se, assim, a pluralidade de mecanismos repetitivos, que termina enfraquecendo seus efeitos. Cabe à Corte, por sua vez, observar o tempo de duração das medidas emergenciais, sem deixar de lado a possibilidade de iniciar procedimento padrão na Comissão. Vale lembrar que medidas provisórias de duração demasiadamente longa colocam em questão a natureza do próprio instituto, que deveria condicionar sua validade às situações de extrema gravidade e urgência.

\section{Desafios internos nos países}

A promoção e difusão do SIDH entre os diferentes órgãos das esferas federal, estadual e municipal, incluindo os poderes Executivo, Legislativo e Judiciário, é essencial para a melhora no cumprimento e execução local das decisões emanadas pelos órgãos do Sistema.

No caso do Brasil, por exemplo, que adota o sistema federativo de organização política, a existência da soberania da União e da autonomia das entidades federadas (estados, municípios e Distrito Federal) acarreta importante obstáculo no cumprimento e na execução das decisões dos órgãos do SIDH, pois os entes federados 
não participam do engajamento do Estado brasileiro nos compromissos internacionais, representado pelo Poder Executivo federal.

O maior desafio interno a ser enfrentado é sensibilizar os demais entes da federação (muitos deles governados por forças políticas que exercem oposição virulenta ao governo central) para a ideia de que os compromissos assumidos internacionalmente são de responsabilidade de todos, não apenas do governo federal. A maior dificuldade está em difundir a noção de compartilhamento de responsabilidades, na qual todos os atores exercem papel relevante e fundamental.

O estreitamento de cooperação entre os três poderes republicanos deve ser igualmente estimulado, pois permite elaborar e implementar ações integradas no sentido de cumprir com as determinações do Sistema. Qualquer estudioso das instituições políticas das três Américas sabe o 152 quanto podem ser profundas e até inconciliáveis as divergências internas entre os poderes republicanos de cada país, litígio que vem resultando em episódios de virtual golpe de Estado - Honduras e Paraguai - ou em tensionamentos crescentes - como os verificados na Venezuela, na Bolívia, no Equador, entre outros países.

Outro mecanismo imprescindível para o cumprimento e a execução das decisões é a elaboração de legislação específica dispondo sobre o procedimento interno a ser adotado. Um mecanismo dessa natureza evita que práticas públicas caiam no esquecimento em função de mudanças na conjuntura política, permitindo a consolidação de verdadeiras políticas de Estado em prol do fortalecimento do Sistema Interamericano de Direitos Humanos.

Se a finalidade do SIDH fosse unicamente receber denúncias e processá-las com rigor, contaria com melhores argumentos a seu favor a estratégia de priorizar as denúncias relativas a cada país, sem preocupação com qualquer 
tipo de limite, cadência e ritmo dessa pressão. Estaríamos diante de algo na linha "duela a quien duela", estratégia geralmente errada e que seria simbolizada pela imagem de defensores de direitos humanos com um tridente na mão, quando, nesse território muito especial do avanço civilizatório, não se pode admitir nenhum tipo de fundamentalismo principista. E muito menos ignorar o reconhecimento de alteridade que é um pressuposto básico tanto da ideia democrática quanto dos fundamentos mais gerais dos direitos humanos.

Ocorre, no entanto, que o Sistema tem como finalidade igualmente precípua o trabalho de promoção dos direitos humanos - em tese, a promoção se refere ao trabalho para que os países da região passem a exibir, a cada ano, indicadores mais positivos a respeito das violações e de seu adequado processamento.

Só mentalidades fundamentalistas poderiam sustentar que a melhor forma de garantir esse avanço é reiterar invariavelmente as pressões e denúncias, sem qualquer contraponto no estabelecimento de parcerias e programas de cooperação: elaboração ou atualização dos Planos Nacionais de Direitos Humanos de cada Estado-membro, recomendado pela Conferência de Viena; preparação de campanhas temáticas em cada país (direitos da criança, equidade de gênero, combate à homofobia, inclusão racial e social); organização de cursos e seminários na área da educação em direitos humanos etc.

Dois episódios mais recentes ilustram a importância de levar em conta as dinâmicas políticas, sociais e históricas internas a cada país no processamento de cada caso levado à Comissão ou à Corte. Um deles é o da Venezuela. Mesmo que o SIDH tenha toneladas de razão nas advertências e medidas endereçadas contra o governo Chávez, em sã consciência nenhum defensor dos direitos humanos pode comemorar o fato concreto de que nas eleições 
presidências de 2012, a direita mais reacionária daquele país - que nunca teve qualquer compromisso com os direitos humanos - tenha se apropriado da agenda da CIDH e operado com êxito no sentido de identificá-la com a agenda da SIP.

No Brasil, o início de 2011 foi marcado por um inesperado choque entre a CIDH e o governo recém-empossado de Dilma Roussef. A posse era carregada de forte simbolismo em favor da agenda nacional dos direitos humanos. Por um lado, ela tinha sido eleita como continuadora do bem avaliado governo Lula, que pautou expressivos avanços com o Fome Zero e o Bolsa Família, programas de inclusão escolar, combate a desigualdades regionais e à discriminação racial, criação de um ministério dos Direitos Humanos e aprovação do corajoso Programa Nacional de Direitos Humanos (PNDH-3), que despertou furiosa reação conservadora devido ao compromisso de instalar, finalmente, uma Comissão

154 Nacional da Verdade para examinar todas as violações ocorridas durante a ditadura militar.

De outro lado, era a primeira vez que uma mulher assumia o posto de autoridade política principal, em mais de 500 anos de história, e ressalte-se que a igualdade entre homens e mulheres em todos os planos (quase ignorada no texto da Declaração Universal dos Direitos Humanos, de 1948) precisa ser reconhecida como uma das mais importantes prioridades mundiais neste início de século XXI. Não apenas uma mulher. Uma mulher muito especial, que, aos 23 anos de idade, sobreviveu às torturas brutais a que foi submetida, em 1970, nos odiosos porões do aparelho repressor que dizimou a juventude que enfrentava a tirania.

Merece registro, aqui, para ligar essa recordação histórica às advertências já feitas quanto aos riscos de o SIDH ser associado à SIP, que aquele massacre, assim como o ocorrido no Uruguai, na Argentina, no Chile e em outros países, 
ocorreu sob aplausos e apoio incondicional dos órgãos de imprensa articulados regionalmente como SIP, com exceção dos breves períodos em que o aparelho repressor voltou-se também contra a imprensa que tinha ajudado a criá-lo, tal qual Saturno devorando os próprios filhos.

Por último, já em seus discursos de candidata vitoriosa e no dia da posse, Dilma tinha dado relevo maior à abordagem dos temas específicos dos direitos humanos do que era costume no período de Lula. Toda essa festa foi interrompida abruptamente quando a nova presidenta reagiu a uma intervenção da CIDH a respeito da construção da usina hidrelétrica de Belo Monte, na Amazônia brasileira.

Não cabendo examinar de forma detalhada aquele episódio, vale focalizar um aspecto muito importante que os jornais deixaram de lado, e mesmo as entidades vinculadas à defesa dos direitos humanos parecem ter ignorado. Trata-se da seguinte questão: não é apenas entre as classes sociais e entre os poderes republicanos de cada país que ocorrem disputas permanentes em torno dos temas dos direitos humanos, mas também no interior de um mesmo governo, sobretudo nos casos em que vigora o chamado presidencialismo de coalizão. Já era assim no período Fernando Henrique Cardoso (1995-2002), que trouxe importantes avanços apesar de resistências opostas por segmentos do próprio governo, foi assim com Lula (2003-2010), é assim com Dilma.

Entre 2007 e 2010, fortaleceu-se bastante, no interior do governo Lula, a ala decidida a superar todas as barreiras opostas ao exame investigativo do período ditatorial. Nesse embate interno, apoiado pelas entidades da sociedade civil ligadas aos direitos humanos, esse segmento buscou apoiar-se enfaticamente na autoridade do SIDH para convencer os segmentos adversários, argumentando, principalmente, com a expectativa iminente de uma condenação do Brasil no caso da Guerrilha do Araguaia. 
Essa ala manteve duras controvérsias com o Ministério da Defesa, com a Advocacia Geral da União e mesmo com o Ministério de Relações Exteriores, sustentando sempre, com firmeza e determinação, que o governo Lula deveria seguir incondicionalmente as orientações jurídicas e políticas emanadas da CIDH e da Corte.

Esse choque foi particularmente difícil no momento de o Executivo federal apresentar seu parecer ao exame, pelo Supremo Tribunal Federal (STF), de uma ação sobre a inconstitucionalidade da Lei de Anistia de 1979 (típica autoanistia na jurisprudência da Corte Interamericana), rejeitando a interpretação de que aquela lei da ditadura impedia ainda hoje a investigação e responsabilização dos torturadores.

Em abril de 2011, o anúncio repentino pela CIDH de sua determinação de que fossem imediatamente paralisadas as obras da hidrelétrica do rio Xingu valeu como 156 verdadeiro tiro no peito dessa ala interna compromissada com a agenda dos direitos humanos. Os setores adversários correram para a imprensa argumentando que decisões irresponsáveis como aquela não poderiam ser acatadas em hipótese alguma pelo país, por agredirem a soberania nacional.

Em resumo: seja pela pressa, seja pela falta de assessorias mais amplas ou qualificadas, seja por insensibilidade diante do contexto político interno de cada país, seja ainda por alguma espécie de ultra-ativismo temático da responsável norte-americana, então presidindo a Comissão, o fato é que a decisão jogou por terra anos de empenho de autoridades públicas brasileiras alinhadas com o esforço de fortalecimento do SIDH e a internalização plena de toda a sua normatividade e jurisprudência.

Abriu-se gigantesca brecha para que o segmento conservador, enfraquecido pelo anúncio, quatro meses antes, da sentença condenatória da Corte Interamericana a res- 
peito da Guerrilha do Araguaia - que incluiu uma clara determinação no sentido de que a Anistia de 1979 não siga representando obstáculo à investigação plena daquele episódio - passasse a explorar o erro da Comissão para atacar, com esperteza, o acerto da Comissão e da Corte no episódio referente à ditadura.

\section{Necessidade de reforma no sistema}

Discussões, estudos e diálogos sobre o funcionamento do Sistema Interamericano de Direitos Humanos já remontam ao final da década de 1990, o que contribui no sentido de que todos os atores relevantes possam opinar de maneira aprofundada e abrangente sobre os principais desafios e possíveis mudanças para que ele se fortaleça e atenda melhor a suas funções de promoção e proteção.

A crise recente provocou uma aceleração - talvez excessiva - nos trâmites da pretendida e necessária reforma. Cabe perguntar, aqui, se não caberia uma primeira intervenção propondo que os debates se estendam até o final de 2013, dando espaço a estudos e discussões mais serenas. No Brasil, importantes centros de excelência, como a Conectas Direitos Humanos e o Departamento de Ciência Política da Universidade de São Paulo, já iniciaram ou preparam estudos e seminários, que não conseguiram resultar em frutos consistentes no prazo exíguo de março de 2013.

O novo Secretário-Executivo da CIDH, Emilio Alvarez Icaza, também vem sinalizando uma nova atitude acerca da reforma. Trabalha na reabertura de diálogo com a Venezuela, para que aquele país reveja sua atitude drástica, e se alinha com a ideia de que bloquear qualquer reforma seria um caminho fadado à derrota. Em novembro de 2012, durante o $146^{\circ}$ Período de Sessões Ordinárias da Comissão, novos passos desse debate foram dados, ouvindo-se em separado os representantes dos Estados e 62 organizações da sociedade civil de diferentes países. 
Sem prejuízo da riqueza desses debates e da diversidade de pontos de vista e de propostas de reforma nele veiculados, é preocupante a falta de maiores avanços em direção a uma reestruturação abrangente do Sistema que, conforme avaliado por diversos Estados e outros atores, poderia envolver mudanças na própria Convenção Americana, numa perspectiva mais ambiciosa.

Em paralelo ao desenvolvimento do diálogo no âmbito do Conselho Permanente, sabe-se que o número de petições, casos e medidas cautelares e provisórias na Comissão e na Corte aumentou em ritmo ainda mais intenso do que já ocorria. Esse aumento agrava tanto a sobrecarga do Sistema - que já vem sofrendo os mesmos problemas de demora injustificada que costuma condenar - quanto percepções de que o recurso ao Sistema Interamericano estaria sendo abusado ou desvirtuado.

Para tanto, concorreria um entendimento ultralibe158 ral dado aos requisitos de admissibilidade. Os desafios à universalidade do SIDH, no entanto, persistem e parecem tender a um agravamento, com relatos de que altas autoridades de Estados comprometidos com o Sistema estariam declarando abertamente que não cumprirão decisões de seus órgãos.

A falta de universalidade repercute fundamentalmente no problema da supervisão do cumprimento das decisões do Sistema pelos órgãos políticos da OEA. A posição do Estado brasileiro tem considerado haver um risco grave de seletividade (mesma doença responsável pela paralisação da Comissão de Direitos Humanos da ONU, em Genebra, antes de se converter em Conselho) no âmbito regional americano.

Não podem ficar em segundo plano as discussões para equacionar a quebra de isonomia ou, pelo menos, a assimetria que resulta das propostas que possibilitam a alguns Estados, que não são parte do Pacto de São José e/ou não 
reconheceram a jurisdição contenciosa da Corte, venham, por meio dos órgãos políticos superiores da OEA, ou pelo seu relevante papel no financiamento do sistema de proteção aos direitos humanos, atuar como fiscais e garantidores do cumprimento das decisões do Sistema, sem se submeterem a ele.

É igualmente preocupante, no contexto acima descrito, que as reformas até então ocorridas concentrem-se exclusivamente em mudanças que a Comissão e a Corte vêm realizando em seus próprios regulamentos. As sucessivas reformas nos Regulamentos da Comissão e da Corte Interamericanas introduziram mudanças importantes na tramitação de petições e medidas cautelares ou provisórias no sistema, em favor de maior participação das vítimas e de maior economia e celeridade processuais, despertando ao mesmo tempo críticas quanto ao déficit que esse tipo de autorreforma exibiria no quesito da chamada accountability.

Ao lado desses aspectos positivos, contudo, têm ocorrido mudanças que às vezes interferem em temas que caberiam exclusivamente à Convenção Americana regular e que, muitas vezes, fragilizam o princípio da "igualdade de armas" em detrimento dos Estados.

Tome-se, por exemplo, as alterações no Regulamento da Comissão Interamericana de Direitos Humanos, no que se refere aos prazos em petições de "casos sérios e urgentes, ou quando se crê que a vida ou a integridade pessoal de uma pessoa esteja em perigo iminente". A CIDH atribuiu-se o direito de solicitar a "resposta mais rápida possível” dos Estados, que poderá ser sobre admissibilidade e mérito ao mesmo tempo (artigos 30, 30.4 e 30.7 do Regulamento). A posição processual dos Estados resta bastante vulnerável diante do controle absoluto que a CIDH se autoatribuiu sobre os prazos nessas situações e do abandono da divisão entre as fases de admissibilidade e 
mérito. Pergunta-se como estariam garantidos o equilíbrio e a igualdade de armas ou a segurança jurídica quando os Estados podem vir a sofrer "procedimentos sumários"?

Para evitar o risco de violações nessas situações graves e urgentes, o procedimento adequado é o de medidas cautelares ou provisórias, que garantem direitos humanos sem sacrificar o exame aprofundado e equilibrado sobre a admissibilidade e o mérito de uma petição. Efetivamente, parece que a CIDH, pela via de seu Regulamento, teria buscado contornar as dúvidas que alguns Estados lançam sobre sua competência para editar medidas cautelares, não prevista no texto da Convenção Americana e um dos pontos importantes para a reforma do Sistema.

Outros exemplos de questões regulamentares controversas são a autoatribuída competência da Comissão para iniciar petições "motu proprio", ao arrepio do disposto na Convenção Americana e em grave atentado contra a 160 igualdade de armas, visto que a CIDH atua ao mesmo tempo nos papéis como parte e como tomador de decisão. A participação direta das vítimas na Corte, embora louvável, tem resultado em que os Estados demandados disponham, como já foi dito, de tempo para se defender inferior ao tempo total reservado aos dois atores que vêm atuando no polo demandante.

Embora tanto a Comissão quanto a Corte disponham de autonomia para adotar e alterar seus regulamentos, desde que observadas as disposições da Convenção e dos Estatutos, maior diálogo e participação dos Estados nesse processo seria recomendável, da mesma forma que os Estados vêm dialogando com a CIDH e a Corte no âmbito das Sessões Especiais. Em qualquer hipótese, não podem as disposições regulamentares contrariar princípios e normas consagrados na Convenção Americana sobre Direitos Humanos e nos Estatutos da Comissão e da Corte; as reformas dos regulamentos não devem servir 
de substituto ou sucedâneo de eventuais reformas no texto convencional.

As sucessivas reformas nos Regulamentos evidenciou a necessidade de rediscutir os Estatutos da CIDH e da Corte. Em 29 de junho de 2011, o Conselho Permanente da OEA criou um Grupo de Trabalho Especial de Reflexão sobre o Funcionamento da Comissão Interamericana de Direitos Humanos para o Fortalecimento do Sistema Interamericano de Direitos Humanos. Em 13 de dezembro de 2011, após ter sido aprovado pelo Grupo de Trabalho, o relatório foi comentado por alguns Estados e sancionado pelo Conselho Permanente em 25 de janeiro de 2012.

Em consequência às reações dos Estados, a $\mathrm{CIDH}$ decidiu, em março de 2012, durante o seu 144 Período de Sessões, iniciar um estudo sobre seus procedimentos e mecanismos e, como parte dessa análise, consultar os atores do Sistema Interamericano. No seu $145^{\circ}$ Período de Sessões, em julho de 2012, elaborou uma agenda para o processo de reforma, que reúne as preocupações e recomendações apresentadas no referido relatório.

No âmbito desse processo, a CIDH submeteu à consulta pública cinco temas, sobre os quais os atores do Sistema poderão enviar seus comentários diretamente à Comissão, a saber: (1) Sistema de Petição Individual, no qual poderão ser levadas as preocupações a respeito dos prazos que regem algumas etapas processuais e a divulgação de critérios e dos mecanismos de que dispõe para tornar mais eficientes e equitativos os procedimentos; (2) Medidas Cautelares, cujo objetivo é proporcionar maior segurança aos atores e maior transparência a suas considerações; (3) Monitoramento da Situação de países, por meio de visitas in loco, visitas de trabalho e relatórios sobre a situação dos direitos humanos nos países; (4) Promoção, na qual se espera receber contribuições que possibilitem o aprimoramento de seu trabalho; e (5) Outros aspectos relacionados 
com o Fortalecimento, que busca ser um espaço aberto para que os atores do Sistema possam levar, ao conhecimento da CIDH, suas inquietudes sobre outros temas de funcionamento do Sistema Interamericano de Proteção dos Direitos Humanos.

Com essa iniciativa, fica claro que a reflexão sobre o funcionamento do sistema e sobre as formas de aperfeiçoá-lo e fortalecê-lo não cabe apenas aos Estados. O fortalecimento do Sistema Interamericano de Direitos Humanos só será efetivo se todos os seus atores refletirem sobre como concorrem para a sua atual situação e sobre como podem contribuir para o seu aperfeiçoamento.

Todos os atores do Sistema deveriam realizar um exercício de autocrítica e assumir a responsabilidade comum pela eficiência da promoção e proteção dos direitos humanos em todas as partes das Américas. Um sistema sobrecarregado, inadequadamente financiado e questionado quan-

162 to ao equilíbrio e à eficácia de suas decisões não interessa às Américas.

\section{Cristina Timponi Cambiaghi}

é advogada, mestre em Direito Internacional Público pelo Instituto de Altos Estudos Internacionais de Genebra, e assessora para assuntos internacionais da presidência da Fundação Nacional do Índio (Funai).

\section{Paulo Vannuchi}

é diretor do Instituto Lula, e foi ministro dos Direitos Humanos no governo Lula, entre dezembro de 2005 e dezembro de 2010. 


\section{Referências bibliográficas}

BOBBIO, N. 2004. A era dos direitos. Rio de Janeiro: Campus.

CIDH. 2012. Processo de reforma 2012: consulta aos atores do Sistema Interamericano de Direitos Humanos. Disponível em: <http://www.oas.org/pt/cidh/fortalecimento/consulta.asp>.

FUKUYAMA, F. 1992. O fim da história e o último homem. Rio de Janeiro: Rocco.

HIRSCHMAN, A. O. 1970. Exit, voice, and loyalty: responses to decline in firms, organizations, and states. Cambridge: Harvard University Press.

LEDESMA, H. F. 2004. El Sistema Interamericano de Protección de los Derechos Humanos: aspectos institucionales y procesales. 3. ed. San Jose: Instituto Interamericano de Derechos Humanos.

SANTOS, B. S. 2012. "Oitava carta às esquerdas: as últimas trincheiras”. Carta Maior, ago. Disponível em: <http://www.cartamaior.com.br/ templates/colunaMostrar.cfm?coluna_id=5737>.

TRINDADE, A. A. C. 1996. Direito internacional e direito interno: sua interação na proteção dos direitos humanos. Disponível em: $<$ http://www.pge.sp.gov.br/centrodeestudos/bibliotecavirtual/ instrumentos/introd.htm $>$.

VIVANCO, J. M. 2012. "Direitos humanos, Insulza e o Brasil”. El Pais, June 6. 


\section{SISTEMA INTERAMERICANO DE DIREITOS HUMANOS: REFORMAR PARA FORTALECER}

CRISTINA TIMPONI CAMBIAGHI

PAULO VANNUCHI

Resumo: O Sistema Interamericano de Direitos Humanos vive hoje tensões e vulnerabilidades que refletem o impacto das profundas mudanças políticas vividas pelos Estados nacionais da região no final do século XX. O fortalecimento da Comissão e da Corte Intermericana de Direitos Humanos nas últimas décadas resultou em natural elevação do rigor com que esses organismos monitoram e tensionam os governos dos países a eles vinculados, gerando reações conflitivas. Tal litígio possui um passado e uma dinâmica histórica que não podem ser desprezados na busca de interpretação adequada dos fatos recentes, com vistas a encontrar soluções e garantir novos ciclos de fortalecimento. Sem esse debate, o sistema corre o risco de ressuscitar a falida anteposição entre direitos de liberdade e direitos de igualdade, como se fosse admissível estabelecer hierarquia entre eles.

Palavras-chave: Direitos Humanos; Sistema Interamericano de Direitos Humanos; OEA; Reforma do Sistema Interamericano dos Direitos Humanos.

\section{INTERAMERICAN SYSTEM OF HUMAN RIGHTS: TO REFORM TO STRENGTHEN IT}

Abstract: The Inter-American System of Human Rights today lives tensions and vulnerabilities that reflect the impact of the profound political changes experienced by the national states of the region in the late 20th century. The strengthening of the Inter-American Commission and Court of Human Rights in recent decades has resulted in natural elevation of the rigor with which these bodies 
monitor and tighten the governments of countries linked to them, creating conflicting reactions. This dispute has a historic past and a dynamic that can not be ignored in the search for appropriate interpretation of recent events, with a view to finding solutions and ensuring new cycles of strengthening. Without this discussion, the system runs the risk of resurrecting the failed anteposition between rights of freedom and rights of equality, as if it were admissible to establish hierarchy between them.

Keywords: Human Rights; Interamerican System of Human Rights; OAS; reform of Interamerican System of Human Rights.

Recebido: 02/05/2013 Aprovado: 15/08/2013 